This is an author produced version of a paper published in Biosystems Engineering.

This paper has been peer-reviewed but may not include the final publisher proof-corrections or pagination.

Citation for the published paper:

von Wachenfelt, Hans; Nilsson, Christer; Ventorp, Michael. (2013)

Measurement of kick loads from horses on stable fittings and building elements. Biosystems Engineering. Volume: 116, Number: 4, pp 487-496. http://dx.doi.org/10.1016/j.biosystemseng.2013.10.013.

Access to the published version may require journal subscription. Published with permission from: Elsevier.

Epsilon Open Archive http://epsilon.slu.se 


\title{
Measurement of kick loads from horses on stable fittings and building elements
}

\author{
Hans von Wachenfelt ${ }^{\mathrm{a}, *}$, Christer Nilsson ${ }^{\mathrm{a}}$, Michael Ventorp ${ }^{\mathrm{a},}$ \\ ${ }^{a}$ Swedish University of Agricultural Sciences, Department of Rural Buildings, P.O. Box \\ 86, SE 23053 Alnarp, Sweden. *E-mail corresponding author: Hans.von.Wachenfelt@slu.se
}

\begin{abstract}
Fittings and fixtures in horse stables may cause injuries to horses when trapped and there is a high risk of an accident to animal and handler when releasing a horse. The risk of injuries to horses and handlers must be minimised by correct structural design and appropriate choice of building material. The physical load of unprovoked and provoked horse kicks were measured in order to obtain data for the design of safe horse fittings and fixtures.

To record the forces exerted by horse kicks a measuring wall and a computerised measuring system were constructed and used in single horse boxes. For reference, the characteristics of the measuring system were determined by a drop hammer test. Through regression analysis a linear relation was found between the field recorded impact values from horse kicks obtained by the measuring system and drop hammer impact values. The drop hammer method can thus be used to test fittings.

Impacts recorded in the field tests were rapid, often shorter than $0.03 \mathrm{~s}$ and $90 \%$ had a maximum value below $1924 \mathrm{~N}$. The greatest impact force and impulse caused by a horse kick were $8722 \mathrm{~N}$ and $131 \mathrm{Ns}$ respectively, with no statistical difference between provoked and unprovoked kicks. Considering the data obtained and allowing a certain safety margin, the impact resistance of horse fixtures and fittings in single horse boxes, to be used for horses of up to $700 \mathrm{~kg}$ mass, should be at least equivalent to $150 \mathrm{Ns}$ exerted by a horse shoe at $45^{\circ}$.
\end{abstract}

Keywords: horse, fitting, structural design, kick, force. 


\section{Introduction}

\subsection{Problem description}

Fittings and fixtures in horse stables, e.g. dividing grids and box wall boards or planks, may cause injuries, for instance when horses kick under-dimensioned structures and the hoof becomes trapped. In addition, there is a risk of injury to humans releasing the trapped horse. To date, according to the author's knowledge, the structural design and appropriate choice of building materials and form have been based on past experience, e.g. by studying and calculating the strength of destroyed constructions. To prevent injuries caused by inadequate design and strength of stable fittings and fixtures, more knowledge is needed about the physical loads (force, impulse, energy) acting when horses kick items in their physical environment. Problems with insufficient strength of tubular steel grids has also focused attention on other parts of the horse box, such as windows, walls, fittings, doors, etc.

Swedish animal welfare legislation and regulations (DSM, 2007) require box and stall walls to have sufficient strength to withstand horse kicks and the design should exclude the possibility of horses becoming trapped by head, jaw or hoof (Figs. 1 and 2). There are design criteria for horse stables but they do not provide mandatory material dimensions or minimal resistance to impact forces. Manufacturers are interested in guidelines and test procedures based on objective information, in order to manufacture safe equipment for horses while still meeting the demand for economical use of materials. At present horse owners/keepers, welfare inspection personnel and equipment manufacturers have difficulties in following the intentions of the welfare legislation because of a lack of objective knowledge about safe stable design.

The design guidelines have to allow manufacturers and building contractors within the horse sector to fulfil the demands of the authorities. The authorities also need data support from objective studies in formulating their requirements.

\subsection{Literature and preliminary work}

There are statistics on horse injuries (Egenwall et al., 2009), but none diagnosed as caused by horse kicks against stable fittings and fixtures. Journal samples from four major Swedish animal hospitals show that the problem exists according to a preliminary survey by the authors. However, there have been studies on human injuries inflicted by horses (Kriss \& Kriss, 1997; Meredith \& Antoun, 2011; Eckert et al., 2011) with horse kicks accounting for approx. $10 \%$ of these injuries (Meredith \& Antoun, 2011). Most of these are attributed to poor handling of horses.

The question "Why horses kick" probably has many answers, but one could be an expression of desperation or provocation like when a horse is broken in to the saddle. The severity of the horse kick depends on the force, but available information on forces experienced by the hoof and limbs comes from experimental measurements of the ground reaction force during normal locomotion or jumping. Dahlin et al. (1973) showed that the maximum vertical force component acting on the forehoof of a trotter at a speed of $6.5 \mathrm{~m} \mathrm{~s}^{-1}$ was about $8000 \mathrm{~N}$. Rooney et al. (1978) found that peak vertical forces were equivalent to $1.75 \mathrm{~N}$ ( $\mathrm{kg}$ body mass) ${ }^{-1}$, i.e. $1120 \mathrm{~N}$, for a horse of $640 \mathrm{~kg}$, for a gallop analysed from one sequence from one horse. Using a force plate, Schambardt et al. (1993) recorded the ground reaction force (GRF) patterns at take-off and landing between the hooves and the ground for all limbs of 5 Dutch Warmbloods $(640 \pm 24 \mathrm{~kg})$ jumping a $0.8 \mathrm{~m}$ vertical fence from the right-leading canter. The GRF parameters were compared to averaged GRF-time patterns of 20 Dutch Warmbloods at the right-leading canter. In the trailing left forelimb (LF), the 
highest vertical GRFs, were found, both in take-off and in landing, to average $13 \mathrm{~N} \mathrm{~kg}^{-1} \mathrm{X}$ body mass, which means $8320 \mathrm{~N}$. Comparable results from 3 examples of LF GRF for jumping horses were approx. $16 \mathrm{~N} \mathrm{~kg}^{-1} \mathrm{x}$ body mass, equivalent to $10240 \mathrm{~N}$.

To be able to determine the energy impact of a horse kick, the kicking velocity of the horse limb is of interest. If the movement of the horse leg kicking can be regarded as a total or a part of an ordinary swing phase at walk, trot or jumping, with a horse hind limb length of $1.35 \mathrm{~m}$ (wither height $1.65 \mathrm{~m}$ ) and a target height of $0.65 \mathrm{~m}$ above the ground level, the kicking distance could be estimated to be $1.35 \mathrm{~m}$. Swing phases at walk, trot, canter and jumping are $0.44,0.40,0.22$ and $0.20 \mathrm{~s}$ respectively according to Johnsen (2003), Hodson et al. (2001) and Schambardt et al. (1993). With a constant distance, the speed can be calculated at the different swing phases, which leaves a probable speed range of 3.1 to $13 \mathrm{~m}$ $\mathrm{s}^{-1}$ if the movement of a kicking horse hind limb can be considered to be a total or a part of the swing phase.

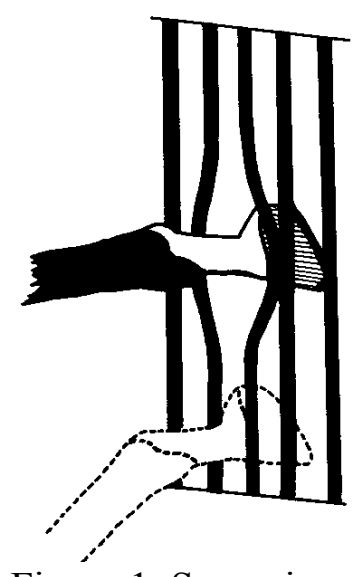

Figure 1. Scenario where a hoof gets trapped in a standing tube grid which is not strong enough and/or has inappropriate tube distance (by permission of Ventorp \& Michanek (1995)).

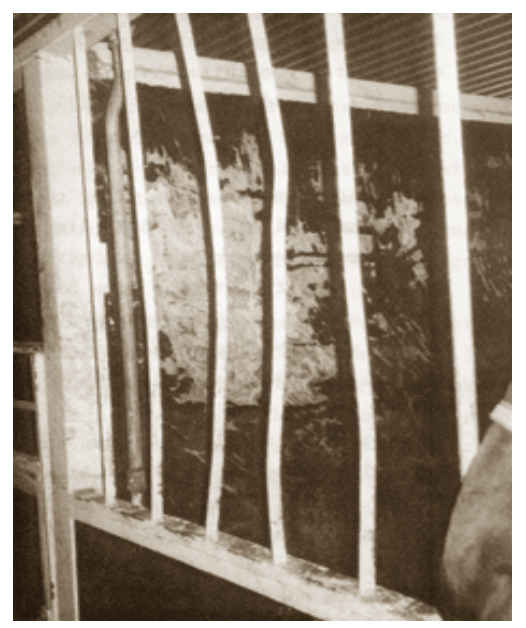

Figure 2. A horse box with poorly designed standing tube grid.

Loads from animals on walls of different materials have been studied by Bergschöld \& Jansson (1976) and also how to measure animal loads (Bergquist, 1978). In a study by Kangro (1987), a constructed measuring wall was used to characterise the loads from finishing pigs $(90 \mathrm{~kg}$ ). A calculated course of impacts that covered $95 \%$ of all recorded impacts had a maximum impact of $550 \mathrm{~N}$ corresponding to 0.6 of the weight (impact weight quotient) of the animals with a duration to maximum impact of $0.17 \mathrm{~s}$ and total duration of $0.42 \mathrm{~s}$. The high loads (exceeding $900 \mathrm{~N}$ ) were evenly spread over twenty-four hours while the rest of the impacts with lower loads occurred during the active part of the day. The highest load registered had a duration of $0.2 \mathrm{~s}$ and was $2144 \mathrm{~N}$, which corresponds to 2.4 times the weight of the animal.

The loads acting on the physical environment of animals can be exerted over a rather long time or can have a very fast, dynamic course (Kangro, 1987). Animal loads on the physical environment have been characterised (SJV, 1995) but no information on the dynamic loads originating from horse kicks has been presented.

In 2007 a pilot investigation of material strength was conducted at Swedish University of Agricultural Sciences (SLU), Department of Rural Buildings and Animal Husbandry (LBT), Alnarp, Sweden, using a drop hammer. The effect of impact kinetic energy on tubular steel grids and wooden boards was studied under specific conditions. The results 
showed that an artificial hoof (drop hammer weight $16 \mathrm{~kg}$, drop height $2 \mathrm{~m}$ ) with a calculated kinetic energy of $324 \mathrm{~J}$ at impact was able to penetrate a prefabricated standard vertical tubular steel grid for horses. The grid dimensions were: tube length $730 \mathrm{~mm}$ with fixed ends, tube diameter $20 \mathrm{~mm}$, tube wall thickness $2 \mathrm{~mm}$ with a spacing between tubes of nominal $68 \mathrm{~mm}$. The drop hammer method has recently been applied when testing and characterising different types of wood and wood-plastic composites (Maikowski, 2011).

\subsection{Aims and objectives}

The overall aim of the present study was to provide data support for guidelines on designing suitable horse box fixtures and fittings and thus significantly reduce the risk of injury to horses.

The first objective was to characterise the loads exerted on the physical environment of unprovoked and provoked (e.g. by a neighbouring horse of different sex) horses through kicks, by using a measuring wall (MW) equipped with load cells and a computerised measuring system. The measurement were to be obtained with no constraints on the horse. The second objective was to propose methods for evaluating and testing different materials and structures in order to allow new constructions of stable structures and fittings to be designed and existing systems to be improved.

\section{Materials and methods}

\subsection{Drop hammer}

The drop hammer used to calibrate the MW, consisted of a frame, a drop shaft and a test ram (Fig. 3). The test ram could be lifted to a maximum of $2.3 \mathrm{~m}$ and released by a handle. The ram was centred by the shaft, had nylon bearings and was also lubricated to minimise friction. The end of the ram was fitted with a horse shoe (size 2) placed at an angle of $45^{\circ}$ so that the shoe tip hit the target.

\subsection{Measuring wall}

\subsubsection{Construction}

The MW measuring system was based on four load sensors (PM20, Chauvin Arnoux, France), with a frequency response of more than $2 \mathrm{kHz}$. The sensors were connected in parallel, with a maximum load carrying capacity of nominal $20 \mathrm{kN}$ (2 tonnes) per sensor, measuring compressive and tensile forces. The four load sensors were connected to an amplifier and a computer-based measuring programme (Strain Gauge Measuring Amplifier GSV-3USB and measuring program, ME-Meßsysteme GmbH, Germany). In use the system recording sampling rate was found to be $238 \mathrm{~Hz}$ instead of the stated nominal sampling rate of $1.2 \mathrm{kHz}$.

The sensors were placed in each corner of a measuring sheet of $22 \mathrm{~mm}$ plywood. The back of the MW, where the sensors were attached, consisted of two U-steel profiles (Fig. 4), with 12 mounting holes in each profile. To provide stability the profiles were connected to a steel frame with flat steel at the short ends. The back of the plywood sheet was reinforced with three 2-mm U-steel profiles along the long ends. To relieve the sensors of the sheet weight when the MW was mounted on a box wall, the plywood sheet and the back of the MW were connected to each other at each of the short ends with rigging screws. Four bolts 
kept the plywood sheet in place at the back of the MW. The rigging screws were adjusted so that the plywood sheet could move against the back of the MW. The bolts were adjusted loosely against the sheet and this strain load was tared off by the measuring system.

The sensors were equipped with ball bearings at the plywood sheet to exclude anything other than direct horizontal forces. The movement of the plywood sheet relative to the ball bearings was approx. $15 \mathrm{~mm}$ laterally and $10 \mathrm{~mm}$ vertically.
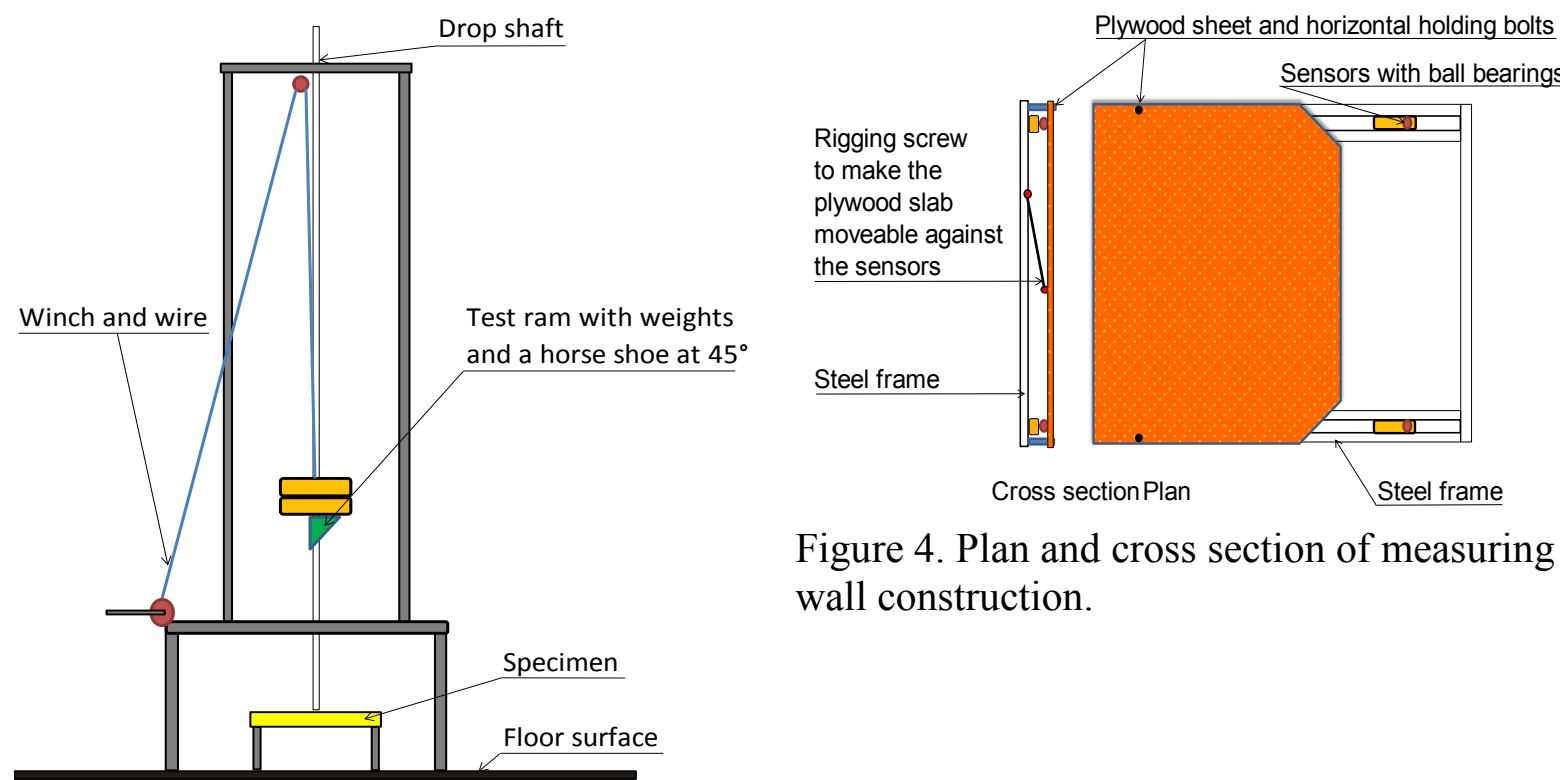

Figure 4. Plan and cross section of measuring wall construction.

Figure 3. Side view of drop hammer construction.

\subsubsection{Calibration}

The MW construction was tested to determine whether the same values could be registered over the whole plywood sheet area. A static calibration test was made by laying the MW on the floor and placing a weight $(32 \mathrm{~kg}$ ) at nine positions along five lines, with 40 samples per measuring point equally spread over the plywood sheet. With the sensors connected in parallel, the mean of the four measured values should correspond with the applied force.

A dynamic impact calibration was made by placing the MW horizontally under a drop hammer and dropping weights $(6.5,16.5,26.5$ and $36.5 \mathrm{~kg})$ from a height of $0.5,1.0,1.5$ and $2.0 \mathrm{~m}$. Ten measurements were made for each weight and height combination of the drop hammer, with the samples distributed over the plywood surface of the MW.

\subsubsection{Data recording and processing}

The force was detected using a computer based measuring program with a sampling rate of $238 \mathrm{~Hz}$. Because the sampling rate of the measuring system was lower than anticipated, a cubic spline interpolation was performed in MATLAB ${ }^{\circledR}$ (MATLAB, 2011) to give an upper magnitude to the peak values. This was partnered by the original peaks representing the lower probable magnitude. By applying the cubic spline interpolation more information can be obtained from the sampled data, making it more robust.

Registered force bouts of significantly longer duration than values from a kick were interpreted as leaning or scratching and were excluded. Calculations were performed in 
Microsoft Excel, where the regression coefficients were obtained through the analysing tool. From the data, the following parameters were derived: horse kick maximum force, horse kick duration and time of the day and night of the horse kick, following the protocol of' Kangro (1987).

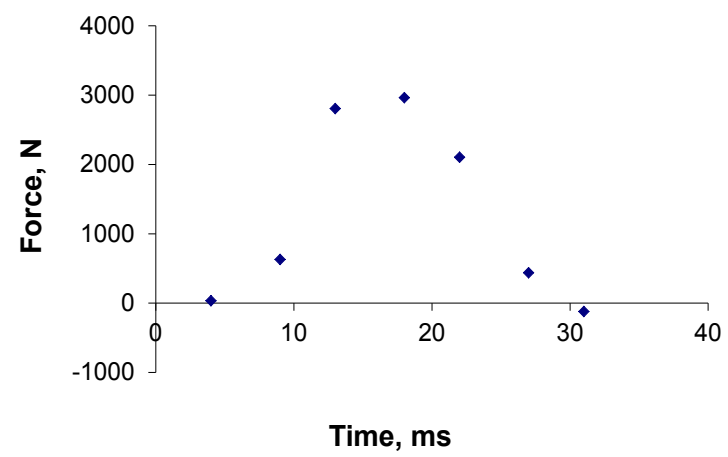

a)

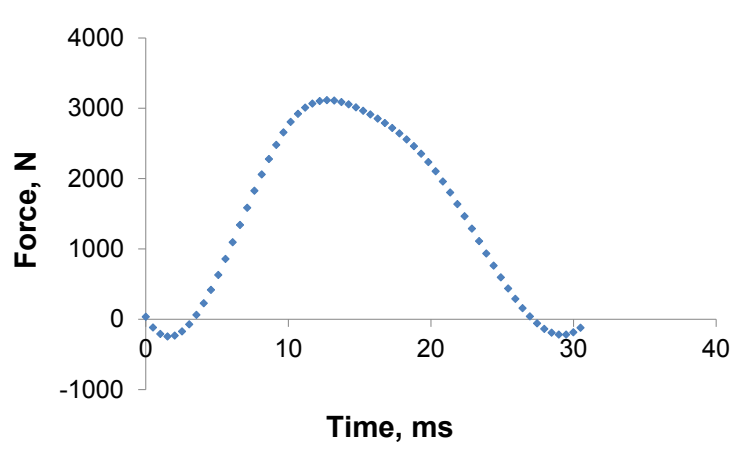

b)

Figure 5. Example of force and duration of a horse kick recorded by the measuring wall system in original (a) and treated by MATLAB ${ }^{\circledR}$ cubic spline interpolation (b).

The energy absorbed by the wall during a kick is of interest, and this could be obtained from the principle of energy conservation $E=(1 / 2) \mathrm{mv}^{2}$ if velocity (v) and effective mass on impact $(\mathrm{m})$ could be measured. The motion of the horses was unconstrained, which meant that hoof velocity on contact could not be measured, because it is extremely difficult to track hoof motion with a high-speed camera under these circumstances. The approach taken in this paper was to first derive a relationship between $E$ and impulse (I) for a controlled drop-hammer experiment, based on the formula $\mathrm{E}=\mathrm{I}^{*} \mathrm{v} / 2$. These data were then compared with impulse values calculated from the MW measurements from unconstrained kicks, as described next, and used to assess the validity of using a drop-hammer test as a means of verifying the safety of walls and fittings in the field.

The impulse principle tells that:

$$
I=\int F d t=m \cdot \Delta v
$$

where $I=$ impulse $(\mathrm{Ns}), F=$ force $(\mathrm{N}), m=$ mass $(\mathrm{kg})$ and $\Delta v=$ change in velocity during impact $\left(\mathrm{m} \mathrm{s}^{-1}\right)$. The integral is the area below the graph in Fig. 5. In the impulse calculations, the integral was approximated to a triangle, where the value of the impulse was derived from the horse kick maximum multiplied by half its duration (Pastell et al., 2008). With a maximum force of $3115 \mathrm{~N}$, the value of the integral is thus $31 \mathrm{~ms} / 2 \times 3115 \mathrm{~N}$ $=48$ Ns. Impulse values were calculated for recorded horse kicks and for the drop hammer impacts. Based on the values from the dynamic impact calibration, theoretical impulse $\left(I_{\mathrm{t}}\right)$ and energy $\left(E_{\mathrm{t}}\right)$ values in Table 1 were determined, where $I_{\mathrm{t}}=m^{*}\left(v_{1}-v_{2}\right)$, and under the assumption of fully inelastic impact, $v_{2}=0$ (no bounce). The drop weight velocity at impact $(v=\sqrt{2 g h})$ and the theoretical energy $\left(E_{\mathrm{t}}\right)$ were calculated from energy conservation. From the recorded MW measurements, impulse $\left(I_{\mathrm{r}}\right)$ and energy $\left(E_{\mathrm{r}}\right)$ values were calculated.

A regression line was determined for recorded $\left(I_{r}\right)$ versus theoretical impulse $\left(I_{t}\right)$ values, where the gradient line could be used as a control of the measuring system (Fig. 6). Another regression line was determined for theoretical impulse $\left(I_{t}\right)$ versus theoretical energy $\left(E_{t}\right)$ values, where the gradient line could be used to evaluate the deformation work of different impulse values (Fig. 7). 


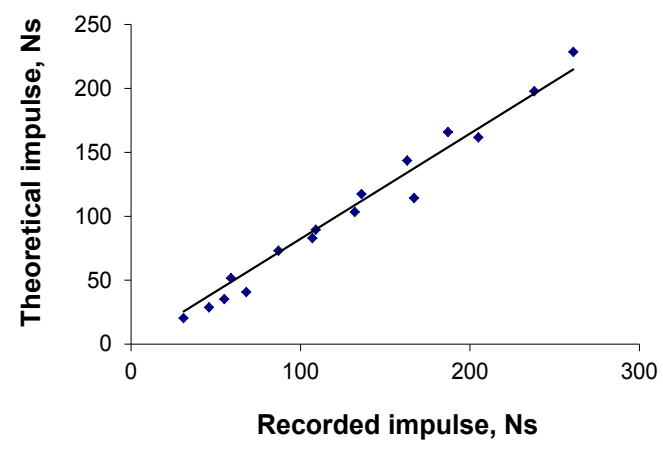

Figure 6. Calibration curve showing the relationship between original recorded impulse values $\left(I_{\mathrm{r}}\right)$ by the MW and theoretically calculated $\left(I_{t}\right)$ using the drop hammer parameters.

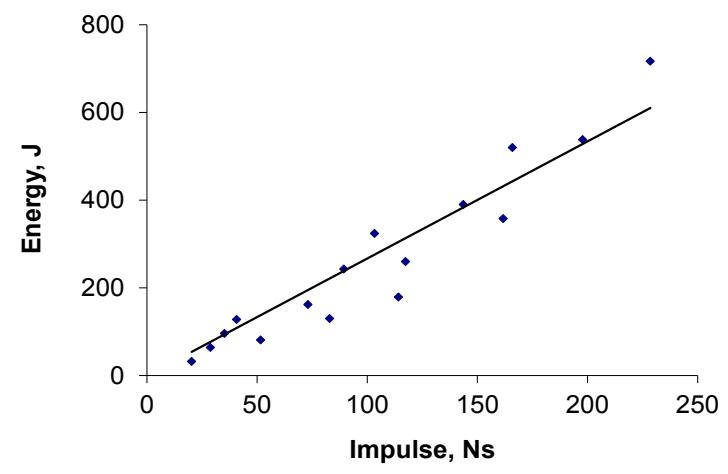

Figure 7. Relationship $(y=2.67 x ; R 2=$ 0.90) between theoretical calculated impulse (It) for the measuring system and theoretical impact energy (Et) based on drop hammer weight and height combinations.

\subsection{Experimental design}

The MW was placed on partition walls in horse boxes with known kicking horses. The MW allowed long-term, continuous measuring periods to be sampled, since the frequency of horse kicks can be low. To only measure forceful horse kicks, a triggering function was used as a sorting mechanism, thus avoiding registration of small kicks or movements less than $100 \mathrm{~N}$ on the MV, e.g. from a horse leaning on it.

Field measurements were carried out at 3 different stables, Uddetorp, Jägersro and Flyingeby. There were differences between the boxes at Jägersro and those at the other two sites in relation to box to box communication and daylight. At Uddetorp and Flyingeby the boxes were open to light and communication, while at Jägersro the partition walls were solid. In total 481 horse kicks were recorded during 6.5 months of measurements. Information on the horses included in the study was provided by the horse owners and the groom at Jägersro.

The first field measurements were made at an agricultural college (Uddetorp, Skara, Sweden). The MW was placed on a partition wall between two horse boxes. Measurements were carried out using two female Swedish warmblood, 9 and 14 years of age, weighing 660 and $550 \mathrm{~kg}$ respectively. Horses of different sexes, placed in the neighbouring box, were used to provoke horse kicks. The 14 year old mare produced unprovoked horsekicks, while the 9 year old only produced horsekicks under provocation.

The horse box walls were made of plywood sheets with steel framework and an upper part of vertical tubular steel grid from $1.4 \mathrm{~m}$ height. The boxes had wood shavings used as litter on the concrete floor.

In the second field experiment the MW was located in a guest stable at a trotter race track (Jägersro, Malmö, Sweden). The horses were stationed in the stable one or two days before a race. For measurements, 11 different trotters were used with an estimated weight of $500 \mathrm{~kg}$. The horse box walls were made of plywood sheets with steel framework all along the walls with a concrete floor and wood shavings as litter.

During the third experiment the MW was placed in a private riding stable (Flyingeby, Lund, Sweden), where the horses had daily training in the mornings and in the afternoons. The measurements were carried out with both unprovoked and with provoked horses using 
three female Swedish warmblood, 3, 4 and 12 years of age, weighing 500, 600 and $550 \mathrm{~kg}$ respectively. The provocations included method of feeding, the order in which the horses were taken out for exercise and by placing a horse in the neighbouring horse box. The box walls in this case were made of horizontal concrete elements with a steel framework and an upper part of vertical tubular steel grid from $1.4 \mathrm{~m}$ height. The floor was of concrete, with peat used as litter.

\subsection{Statistical analysis}

The experimental design was a model with horses as blocks and unprovoked and provoked horses as treatment levels. Analysis of variance was performed in Minitab ${ }^{\mathrm{TM}}$ (Minitab, 2007) to determine the effect of unprovoked and provoked horses on the frequency and magnitude of horse kicks. The statistical model applied was:

$$
Y_{i j}=\mu+\alpha_{i}+\beta_{j}+e_{i j}
$$

where $\mu=$ treatment mean (mean value of maximum impulse per horse) for unprovoked and provoked horses, $\alpha_{i}=$ treatment (unprovoked/provoked horses), $\beta_{j}=$ horse effect and $e_{i j}=$ error term, where $i=1,2$ and $j=1,2,3,4$.

In the data processing, a paired t-test was used for recorded and theoretical calculated impulse values to determine if there were differences between the two datasets in Fig. 6. All data were tested for normal distribution and a significance level of 5\% was used in the analysis. Results are presented as mean and standard deviation (SD).

\section{Results}

\subsection{Calibration of the measuring wall}

The static calibration of the MW system $(32 \mathrm{~kg}$ ) resulted in a mean value of $282(7.8) \mathrm{N}$. The results of the dynamic calibration are shown in Table 1. Drop hammer parameters are displayed at left and are followed by the theoretically calculated values of drop hammer weight velocity, impulse $\left(I_{\mathrm{t}}\right)$ and energy $\left(E_{\mathrm{t}}\right)$ at impact. The MW measurement results are presented as impact duration and maximum impact force recorded at different weights and heights. The theoretical impulse $\left(I_{\mathrm{t}}\right)$ and energy $\left(E_{\mathrm{t}}\right)$ values were calculated and compared with the corresponding impulse $\left(I_{\mathrm{r}}\right)$ and energy $\left(E_{\mathrm{r}}\right)$ values as a control of the measuring system. The original and cubic spline interpolated force values gave a probable range for the peak values.

A relationship was found for the recorded $\left(I_{\mathrm{r}}\right)$ and theoretically $\left(I_{\mathrm{t}}\right)$ calculated impulse values, with a gradient line varying between $\mathrm{y}=0.80 \mathrm{x}$ for the interpolated and $\mathrm{y}=0.82 \mathrm{x}$ for the original values respectively, with correlation coefficients of $R^{2}=0.97$. Because of significant (paired t-test) difference between the recorded and theoretically calculated impulse values, the gradient line relation was used as a correction factor for the field measured values. The gradient line relation in Figure 6 shows that the measuring system overestimated the recorded values. Thus interpolated field values had a lower value than the original after the calibration correction factor had been used.

A relationship was found (Fig. 7) between the recorded impulse $\left(I_{\mathrm{r}}\right)$ and theoretically calculated energy $\left(E_{\mathrm{t}}\right)$ values, with a gradient line of $\mathrm{y}=2.67 \mathrm{x}$ and correlation coefficient of $\mathrm{R}^{2}=0.90$. The gradient line relation was used to calculate the deformation work of field 
Table 1. Theoretical calculated impulse $\left(I_{\mathrm{t}}\right)$ and energy values $\left(E_{\mathrm{t}}\right)$ from the measuring system are compared with minimum and maximum recorded impulse $\left(I_{\mathrm{r}}\right)$ and energy values $\left(E_{\mathrm{r}}\right)$. The measuring results, minimum (original) and maximum (cubic spline treated) values, were derived with measuring wall system placed horizontally under the drop hammer and used for measuring system dynamic calibration (number of samples (n), mean and standard deviation (SD)).

\begin{tabular}{|c|c|c|c|c|c|c|c|c|c|c|c|c|}
\hline \multicolumn{2}{|c|}{$\begin{array}{l}\text { Drop hammer } \\
\text { parameters }\end{array}$} & \multicolumn{3}{|c|}{$\begin{array}{l}\text { Calculated values from drop } \\
\text { hammer parameters }\end{array}$} & \multicolumn{4}{|c|}{ MW measurement results } & \multicolumn{4}{|c|}{$\begin{array}{l}\text { Calculated values from } \\
\text { MW measurement results }\end{array}$} \\
\hline \multirow{3}{*}{$\begin{array}{l}\text { Drop } \\
\text { weight } \\
\text { mass } \\
(m), \mathrm{kg}\end{array}$} & \multirow{3}{*}{$\begin{array}{l}\text { Drop } \\
\text { weight } \\
\text { height } \\
(h), \mathrm{m}\end{array}$} & \multirow{3}{*}{$\begin{array}{l}\text { Drop } \\
\text { weight } \\
\text { velocity } \\
\text { at impact } \\
\left(v_{1}\right), \mathrm{ms}^{-1}\end{array}$} & \multirow{3}{*}{$\begin{array}{l}\text { Impulse } \\
\text { at } \\
\text { impact } \\
\left(I_{t}\right), \mathrm{Ns}\end{array}$} & \multirow{3}{*}{$\begin{array}{l}\text { Energy } \\
\text { at } \\
\text { impact } \\
\left(E_{\mathrm{t}}\right), \mathrm{J}\end{array}$} & \multirow[t]{3}{*}{$\begin{array}{l}\text { Repli- } \\
\text { cations } \\
\text { (n) }\end{array}$} & \multirow{3}{*}{ 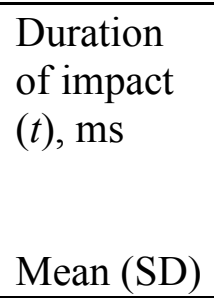 } & \multicolumn{2}{|c|}{ Force of impact $(F), \mathrm{N}$} & \multicolumn{2}{|c|}{$\begin{array}{l}\text { Impulse at impact } \\
\left(I_{\mathrm{r}}\right), \mathrm{Ns}\end{array}$} & \multicolumn{2}{|c|}{$\begin{array}{l}\text { Energy at impact } \\
\left(E_{\mathrm{r}}\right), \mathrm{J}\end{array}$} \\
\hline & & & & & & & Min. & Max & Min. & Max. & Min. & Max. \\
\hline & & & & & & & Mean (SD) & Mean (SD) & \multicolumn{2}{|c|}{ Mean (SD) } & \multicolumn{2}{|c|}{ Mean (SD) } \\
\hline 6.5 & 0.5 & 3.13 & 20.3 & 32 & 10 & $16(0.3)$ & 3904 (234) & $3998(167)$ & $31(2)$ & $32(1)$ & $49(3)$ & $50(2)$ \\
\hline 6.5 & 1.0 & 4.43 & 28.8 & 64 & 10 & $16(0.3)$ & 5708 (199) & $5823(150)$ & $46(2)$ & $46(2)$ & $101(4)$ & $103(4)$ \\
\hline 6.5 & 1.5 & 5.43 & 35.2 & 96 & 10 & $16(0.3)$ & 6841 (414) & 7312 (169) & $55(4)$ & $58(2)$ & 148 (10) & $158(5)$ \\
\hline 6.5 & 2.0 & 6.27 & 40.7 & 128 & 10 & $16(0.3)$ & $8496(381)$ & $8794(180)$ & $68(3)$ & $70(2)$ & $212(10)$ & $219(6)$ \\
\hline 16.5 & 0.5 & 3.13 & 51.6 & 81 & 10 & $15(0.3)$ & $7376(251)$ & $7456(209)$ & $59(2)$ & $59(1)$ & $92(3)$ & $93(2)$ \\
\hline 16.5 & 1.0 & 4.43 & 73.1 & 162 & 10 & $16(0.0)$ & $10845(609)$ & $11068(289)$ & $87(5)$ & $89(2)$ & $192(11)$ & $196(5)$ \\
\hline 16.5 & 1.5 & 5.43 & 89.4 & 243 & 10 & $16(0.0)$ & $13578(571)$ & $13935(358)$ & $109(5)$ & $111(3)$ & 295 (12) & $303(8)$ \\
\hline 16.5 & 2.0 & 6.27 & 103.3 & 324 & 10 & $17(1.0)$ & $15564(865)$ & $16220(237)$ & $132(12)$ & $138(9)$ & $415(36)$ & $432(28)$ \\
\hline 26.5 & 0.5 & 3.13 & 82.9 & 130 & 10 & $25(0.0)$ & 8526 (206) & 8885 (221) & $107(3)$ & $111(3)$ & $167(4)$ & $174(4)$ \\
\hline 26.5 & 1.0 & 4.43 & 117.4 & 260 & 10 & $20(0.0)$ & $13606(529)$ & $13853(148)$ & $136(5)$ & $139(2)$ & 301 (12) & 307 (3) \\
\hline 26.5 & 1.5 & 5.43 & 143.6 & 390 & 10 & $20(0.0)$ & 16263 (1032) & $16625(665)$ & $163(10)$ & $166(7)$ & $442(28)$ & 451 (18) \\
\hline 26.5 & 2.0 & 6.27 & 165.9 & 520 & 10 & $21(0.0)$ & $17794(1672)$ & $18548(962)$ & $187(18)$ & $195(10)$ & $586(55)$ & $611(32)$ \\
\hline 36.5 & 0.5 & 3.13 & 114.2 & 179 & 10 & $31(0.0)$ & 10753 (426) & $11048(372)$ & $167(7)$ & $171(6)$ & $261(10)$ & $268(9)$ \\
\hline 36.5 & 1.0 & 4.43 & 161.7 & 358 & 10 & $25(0.0)$ & $16418(427)$ & $16872(333)$ & $205(5)$ & $211(4)$ & 455 (12) & $467(9)$ \\
\hline 36.5 & 1.5 & 5.43 & 197.8 & 538 & 10 & $24(0.0)$ & $19870(895)$ & $20622(554)$ & $238(11)$ & $247(7)$ & 647 (29) & $672(18)$ \\
\hline 36.5 & 2.0 & 6.27 & 228.5 & 717 & 10 & $25(0.0)$ & $20872(2116)$ & $21459(1743)$ & $261(26)$ & $268(22)$ & $818(83)$ & $841(68)$ \\
\hline
\end{tabular}

$v_{1}=\sqrt{2 g h} ; v_{2}=0 ; I_{\mathrm{t}}=m^{*}\left(v_{1}-v_{2}\right)$, where $v_{2}=0 ; E_{\mathrm{t}}=m g h ; I_{\mathrm{r}}=F^{*} t / 2, E_{\mathrm{r}}=I^{*} v_{1} / 2$ 
measured impact values within the range of impact velocities $\left(3.13\right.$ and $\left.6.27 \mathrm{~m} \mathrm{~s}^{-1}\right)$ given by the drop hammer (Table 1).

\subsection{Recorded horse kicks against the MW}

After force bouts of longer duration were removed a total of 472 values remained, 215 unprovoked and 257 provoked measurements. The indentations on the MW from the drop hammer impact appeared visually equivalent to real impacts from horse hooves (Fig. 8).

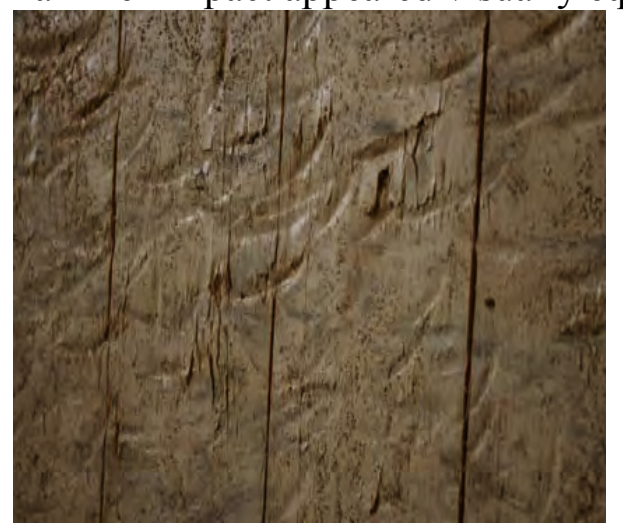

Figure 8. Real impacts from horse hooves on box planks.

The results of the compiled measurements are shown in Figs. 9 and 10. Most of the impacts $(90 \%)$ had a maximum value less than $1924 \mathrm{~N}$ (Fig. 9a), and an impact weight quotient of 0.36 at an weighted impact weight average horse body mass of $566 \mathrm{~kg}$ (Table 2). The highest maximum value obtained was $8700 \mathrm{~N}$ from the cubic spline treated values and $8722 \mathrm{~N}$ for the original measured values. The impact weight quotient for the highest impact value was 1.35 at $660 \mathrm{~kg}$ body mass. Furthermore the total duration of registered impacts was short: $2 \%$ had a duration less than $0.001 \mathrm{~s}$, while the majority of the impacts $(93 \%)$ had a duration between 0.001 and $0.05 \mathrm{~s}$ (Fig. 9b).

The distribution of the impacts through the day showed that they coincided with activities such as morning and evening feeding, but also other activities during the morning (Fig. 10a). No significant difference was observed between the maximum impact force caused by provoked and unprovoked horses (Table 2), but there is an indication that the provoked kicks were harder on average.

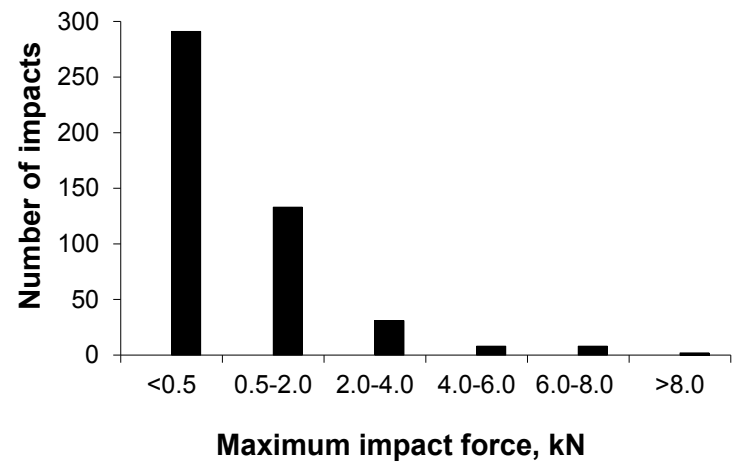

a)

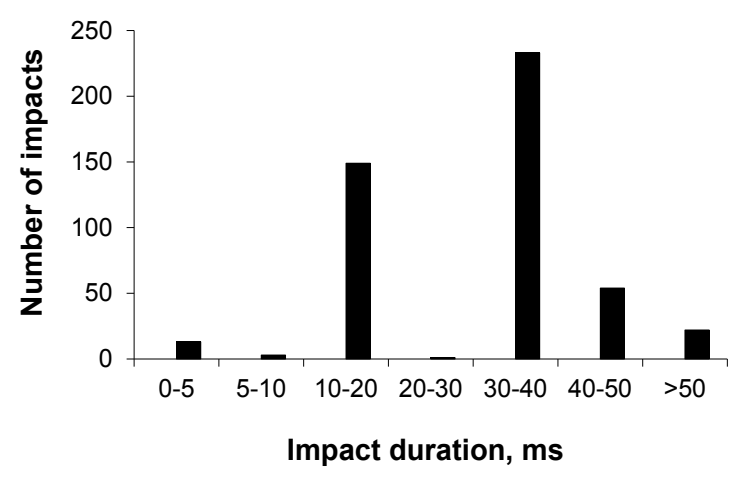

b)

Figure 9 a) Distribution of all recorded maximum forces for impacts $>100 \mathrm{~N}$

b) Distribution of duration for all impacts. 


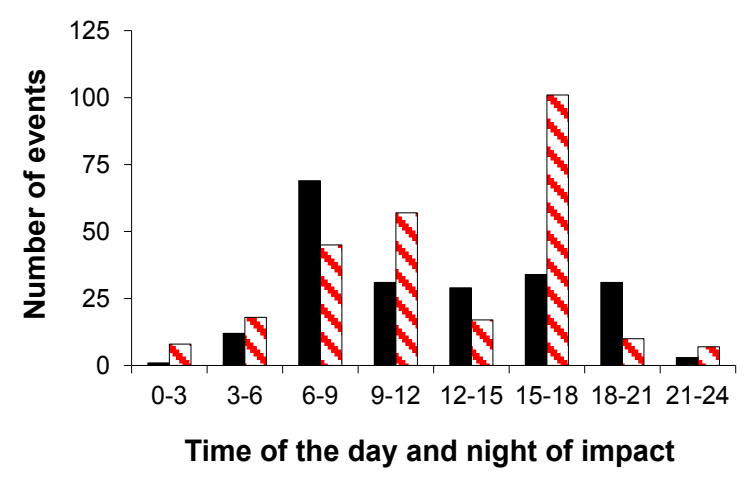

a)

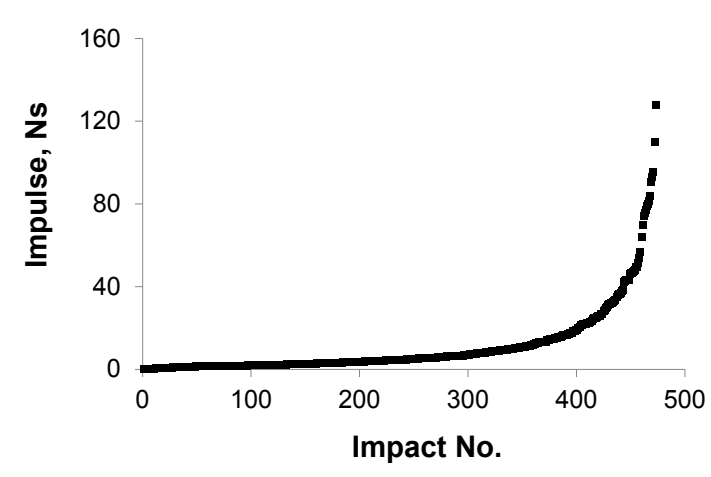

b)

Figure 10 a) Unprovoked (black bar) and provoked horse (hatched bar) activity towards the MW during day and night time.

b) Recorded impulse values, sorted in order of magnitude, for all measured horse kick impacts.

The recorded impulse values from the measurements of horse kicks are displayed as a cumulative series in Figure 10b, sorted in order of magnitude. The greatest impact caused by a horse kick registered in this investigation amounted to an impulse of 131 Ns.

\section{Discussion}

\subsection{The MW}

\subsubsection{The MW construction}

The MW construction, through the elasticity and yield of the plywood sheet material due to its dimensions and the reinforcement steel profiles along the back of the plywood sheet, could affect the recorded impulse and the possibilities for appropriately replicating the experiment.

The possibility that the drop hammer might not meet the ideal situation of free fall, e.g. that a certain amount of friction might arise along the drop hammer shaft, was not accounted for in this study. The system of unloading the sensors from the weight of the plywood sheet may also have influenced the measured results.

\subsubsection{The MW calibration}

The method of using the drop hammer together with the MW was successful. It was possible to use the drop hammer method as a calibration instrument for the MW and in that way the field measuring values could be related to the laboratory method. The relatively steady measurement values derived when using the drop hammer on the MW could characterise the MW working process and indirectly give a quantitative measure of the MW construction. The MW was calibrated with methods that could be considered reasonably easy to replicate. Because of the lower than optimal sampling rate of the measuring system, the cubic spline interpolation was used together with the original recorded values to give an estimate of a lower and upper probable magnitude of the peak values, making the obtained horse kicking data set more robust. 


\subsection{Field measurement values}

The impact duration of the drop hammer (Table 1) is within the range of the measured kick duration (Fig. 9b), but was 10-100 fold shorter than the duration range of animals reported by Kangro (1987). In the present study, the range of the horse kick impact forces could be compared with the range of vertical forces from trotters (Dahlin et al., 1973) and jumping horses (Schambardt et al., 1993), and the impact weight quotient was in the same range for pigs and horses for $90 \%$ of the impacts (Kangro 1987). Due to the short duration of the highest recorded impact value, its impulse value was rated in $13^{\text {th }}$ place. However, it is difficult to determine how representative the recorded horse kick values are in terms of maximum impact for horses in general, as only a limited number of horses were included in this experiment. An indicator of this could be that the highest impact load from pigs was 2.4 times the weight of the animal compared to 1.35 from a horse in this study.

\subsection{Statistical results}

The single horse box design differed by having either solid walls to neighbouring boxes (Jägersro) or a more open horse box of plywood or concrete wall, with standard vertical bars from $1.4 \mathrm{~m}$ height. The 11 horses used in the box with solid walls were all trotters, while the others were riding horses. The trotters were classified as unprovoked horses. When comparing their test data with the other horses, their low maximum impact values and SD agreed with the values documented for unprovoked horses. Whether the kicking behaviour of the trotters was influenced by the box design was not further investigated. However, it is generally considered that standardbreds (trotters) are calmer than riding horses and thoroughbreds.

Table 2. The effect of unprovoked and provoked horses on the maximum impact force of horse kicks. The experimental design was a model with horses as blocks and unprovoked and provoked horses as treatment levels (number of samples (n), means and standard deviation (SD)).

\begin{tabular}{|c|c|c|c|c|c|c|c|c|}
\hline \multirow[t]{3}{*}{ Horse } & \multirow[t]{3}{*}{ Place $^{\mathrm{a}}$} & \multirow{3}{*}{$\begin{array}{c}\text { Weight } \\
\text { kg }\end{array}$} & \multirow{2}{*}{\multicolumn{2}{|c|}{$\begin{array}{c}\text { Unprovoked } \\
\text { Impuls, Ns }\end{array}$}} & \multirow[t]{3}{*}{ Horse } & \multicolumn{2}{|c|}{ Provoked } & \multirow[b]{3}{*}{$p^{d}$} \\
\hline & & & & & & & Impuls, Ns & \\
\hline & & & $\mathrm{n}$ & Mean (SD) & & $\mathrm{n}$ & Mean (SD) & \\
\hline 1 & Udd & 550,660 & 89 & $7.8(8.8)$ & $1+2^{b}$ & 130 & $26.8(28.9)$ & $0.116 \mathrm{~ns}$ \\
\hline $3^{c}$ & Jäg & 500 & 61 & $3.0(2.2)$ & 3 & - & - & \\
\hline 4 & Fly & 550 & 41 & $3.5(2.8)$ & 4 & 19 & $6.1(8.9)$ & \\
\hline 5 & Fly & 600 & 22 & $2.6(2.5)$ & 5 & 17 & $6.1(4.9)$ & \\
\hline 6 & Fly & 500 & 2 & $2.4(0.9)$ & 6 & 91 & $10.5(10.6)$ & \\
\hline
\end{tabular}

a) Udd = Uddetorp, Jäg = Jägersro, Fly = Flyingeby

b) Uddetorp horses were tested as one horse

c) Jägersro horses were left out of the analysis

d) Significance level comparing unprovoked and provoked horses: ns = none significant.

To examine whether the factor provoked and unprovoked horses had an effect in the statistical model, analysis of variance was conducted for all horses in the experiment. The main factor in the statistical model proved to be strong and an almost statistically significant difference was obtained, but with a small number of horses in the different groups. Horse kicks took place at different frequencies and therefore the measurements became extended in time. 


\subsection{Design considerations}

In testing materials and as a guideline for the structural design of horse boxes, the dimensioning value used has to be based on general considerations. The highest recorded impact value from the field measurements corresponded to an impulse value $\left(I_{\mathrm{r}}\right)$ of $131 \mathrm{Ns}$, which is equivalent to a theoretical impact energy $\left(E_{t}\right)$ of $350 \mathrm{~J}(2.67 \times 131)$, where 2.67 is the coefficient of the gradient line between theoretical calculated impulse $\left(I_{t}\right)$ and impact energy $\left(E_{\mathrm{t}}\right)$ based on all drop hammer weight and height combinations (Table 1 and Figure 7 ). This impact energy is consistent with the amount of energy needed (drop hammer weight $16.5 \mathrm{~kg}$, height $2 \mathrm{~m}$ ) to deform a standard vertical tubular steel grid to penetration according to the previous pilot test performed at the Department.

The parameter of interest for designing box fittings and structures to resist horse kicks is the impact energy. As a safety margin $150 \mathrm{Ns}$ is proposed instead of $131 \mathrm{Ns}$. This limit value of $150 \mathrm{Ns}$ corresponds to a theoretical impact energy $\left(E_{t}\right)$ of $400 \mathrm{~J}(2.67 \times 150)$. Furthermore, the horse hoof velocity at impact is assumed to be $3.13-6.27 \mathrm{~m} \mathrm{~s}^{-1}$, which was the velocity range of the drop hammer in the laboratory tests. It is likely that hoof velocity at impact can be faster resulting in greater impact energy in relation to impulse. Analysis of a kicking horse, filmed with an ordinary video camera (30 frames per second), indicates a hoof velocity of approx. $12 \mathrm{~m} \mathrm{~s}^{-1}$ (range $8-16 \mathrm{~m} \mathrm{~s}^{-1}$ ) at impact. The same velocity range could be calculated based on the swing phases of trotters and jumping horses (Johnsen, 2003; Hodson et al., 2001; Schambardt et al., 1993). This make sense if comparing the full speed of a racing Standardbred trotter and considering the required rear hoof velocity when pushing the horse onwards. If the hoof velocity at impact is $10 \mathrm{~m} \mathrm{~s}^{-1}$, the impact energy at impulse of $150 \mathrm{Ns}$ will be $750 \mathrm{~J}$. However, actual hoof velocities should be confirmed in future studies.

Based on existing knowledge, it can be concluded that building materials and forms designed for horses up to $700 \mathrm{~kg}$ weight should be able to withstand $150 \mathrm{Ns}$ impulse resulting from a point load from a corresponding horse shoe. A horse weight of $700 \mathrm{~kg}$ was chosen here because it is used in Swedish Standards (SIS, 2012). The recorded impact values in the field experiment were increased by $15 \%$, which can be considered to be a reasonable minimum safety margin. This consideration takes into account the fact that the largest horse included in the experiment had a weight of $660 \mathrm{~kg}$ and that we probably did not record the hardest kick possible by a horse.

\section{Conclusions}

The aim was to provide data support for guidelines on designing suitable horse box fixtures and fittings and thus significantly reduce the risk of injury to horses.

A measuring wall was developed and placed in horse boxes where it was able to measure impact force and impact duration of a horse kick. Through regression analysis a linear relation was found between the field recorded impact values from horse kicks obtained by the measuring system and drop hammer impact values. The drop hammer method can thus be used for testing of fittings.

The impact of a horse kick is rapid, often shorter than $0.03 \mathrm{~s}$. The greatest impact caused by a horse kick registered in the study amounted to $8722 \mathrm{~N}$ and 131 Ns respectively. Provocation of horses did not result in statistically harder kicks. Considering the recorded values and taking into account a certain safety margin, the impact resistance requirement for conventional horse boxes to be used for maximum $700 \mathrm{~kg}$ horses should be at least equivalent to $150 \mathrm{Ns}$ caused by a hit of a horse shoe inclined at $45^{\circ}$. 
In order to obtain more statistically significant data, leading to more accurate design values, extended measurements, supplemented with kicking speed measurements, should be carried out on greater numbers of horses. Horses are probably able to kick harder than was recorded in our study.

\section{Acknowledgements}

The authors gratefully acknowledge financial support from the Swedish Board of Agriculture, Alnarp Partnership, Swedish Rural Economy and Agricultural Societies (Malmöhus County, Sweden), and the Swedish Farmers Accident Insurance Fund for the research work reported in this paper. A special thanks to Johanna Gustafsson, Olle Lindgren and Katri Wäyrynen and to Jan-Eric Englund for statistical advice.

\section{References}

Bergquist, A. 1978. Load measurements - Development of methods for measurement of loads from domestic animals. Swedish University of Agricultural Sciences, Department of Farm Buildings. Report No. 1. Lund.

Bergschöld, B. \& Jansson, I. 1976. Strength of sheets for livestock houses (Hållfasthet hos skivor i stallar). Swedish University of Agricultural Sciences, Department of Farm Buildings. Special Report No. 59. Lund.

DSM. 2007. Djurskyddsmyndighetens föreskrifter och allmänna råd om hästhållning. Djurskyddsmyndigheten (Jordbruksverket), [Regulations of Swedish Animal Welfare Agency about horse keeping. Swedish Animal Welfare Agency (Swedish Board of Agriculture), DFS 2007:6 \# L101] DFS 2007:6. Saknr L101.

Dahlin, G., Drevemo, S., Fredricson, I., Jonsson, K. and Nilsson, G. 1973. Ergonomic aspects of locomot asymmetry in Standardbred horses trotting through turns. Acta Veterinaria Scandinavica, suppl. 44, 111-139.

Eckert, V., Lockemann, U., Puschel, K., Meenen, N. and Hessler, C. 2011. Equestrian Injuries Caused by Horse Kicks: First Results of a Prospective Multicenter Study. Institute of Legal Medicine, University Medical Center Hamburg-Eppendorf, Hamburg, Germany. Clinical Journal of Sport Medicine 21(4):353-355.

Egenwall, A., Lönnell, C. and Roepstorff, L. 2009. Analysis of morbidity and mortality data in riding school horses, with special regard to locomotor problems. Preventive Veterinary Medicine 88 (2009) 193-204.

Hodson, E., Clayton, H. M. and Lanovaz, J. L. 2001. The hindlimb in walking horses: 1. Kinematics and ground reaction forces. Equine Veterinary Journal, 33, 38-43.

Johnsen, D. A .J. 2003. Why trot when you can walk? An Investigation of the Walk-Trot Transition in the Horse. Master of Science thesis. California State Polytechnic University, Department of Biological Sciences, Pomona.

Kangro, A. 1987. Loads from animals, measurements and analysis. Rapport 55. Swedish University of Agricultural Sciences, Department of Farm Buildings, Division of Agricultural Building Technology, Lund.

MATLAB. 2011. MATLAB ${ }^{\circledR}$ R2011b. The MathWorks Inc., Natick, MA, USA.

Maikowski, S. 2011. Technologische Untersuchung der Einsatzmöglichkeiten von plattenförmigen WPC für die Pferdehaltung. Universität Hamburg. Master of Science thesis. Universität Hamburg, Fakultät für Mathematik, Informatik und Naturwissenschaften, Department Biologie, Zentrum Holzwirtschaft. Hamburg.

Meredith, L. and Antoun, J.S. 2011. Horse-related facial injuries: the perceptions and experiences of riding schools. Injury Prevention 17:55-57.

Minitab. 2007. Minitab Release 15 for Windows, Minitab Inc., State College, PA, USA. 
Pastell, M., Kujala, M., Aisla, A-M., Hautala, M., Poikalainen, V., Praks, J., Veermäe, I. and Ahokas, J. 2008. Detecting cow's lameness using force sensors. Computer and Electronics in Agriculture 64, 34-38.

Rooney, J. R., Quddus, M. A. and Kingsbury, H. B. 1978. A laboratory investigation of the function of the stay apparatus of the equine foreleg. Journal of Equine Medical Surgeon, $2,173-180$.

Schambardt, H.C., Merkens, H.W., Vogel, V. and Willekens, C. 1993. External loads on the limbs of jumping horses at take-off and landing. American journal of veterinary reasearch, 54(5), 675-680.

SIS. 2012. Ekonomibyggnader - tillämpningar till Boverkets och Jordbruksverkets regler avseende utformning av ekonomibyggnader för jordbruk, skogsbruk och trädgårdsnäring samt hästverksamhet [Farm buildings -applications of regulations issued by the National Board of Housing, Building and Planning and the National Board of Agriculture related to the design of buildings for farming, forestry, horticulture, and horse activities]. Swedish Standards Institute. Teknisk Specifikation, TS 37. Stockholm.

SJV. 1995. Building Guidance of the Board of Agriculture - Farm Buildings Handbook. Jönköping (In Swedish), Swedish Board of Agriculture.

Ventorp, M. \& Michanek, P. 1995. Att bygga häststall - en idéhandbok (Building horse stables - an inspiration handbook). Sveriges Lantbruksuniversitet, Inst. för lantbrukets byggnadsteknik. SLU Förvaltningsavdelning, Reproavdelningen. Alnarp. ISBN 91576-6130-8. 